\begin{tabular}{|c|l|}
\hline Title & $\begin{array}{l}\text { Mapping of subsurface karst structure with gamma ray and electrical resistivity profiles : a case study from Pokhara } \\
\text { valley, central Nepal }\end{array}$ \\
\hline Author(s) & Gautam, Pitambar; Pant, Surendra Raj; A ndo, Hisao \\
\hline Citation & $\begin{array}{l}\text { Journal of A pplied Geophysics, 45(2), 97-110 } \\
\text { https://doi.org/10.1016/S0926-9851(00)00022-7 }\end{array}$ \\
\hline Issue Date & $2000-09$ \\
\hline Doc URL & http://hdl.handle.net/2115/42497 \\
\hline Type & article (author version) \\
\hline File Information & np-karst-00.pdf \\
\hline
\end{tabular}

Instructions for use 
Final Manuscript of paper published in

Journal of Applied Geophysics, Volume 45, Issue 2, September 2000, Pages 97-110

\title{
Mapping of subsurface karst structure with gamma ray and electrical resistivity profiles: a case study from Pokhara valley, central Nepal
}

\author{
Pitambar Gautam ${ }^{\S}$, Surendra Raj Pant, Hisao Ando* \\ Central Department of Geology, Tribhuvan University, Kirtipur, Kathmandu, Nepal \\ *Present address: Suimonchishitsu Kenkyuusho (Institute of Hydrogeology Co. Ltd.), Sapporo \\ 060-0004, Japan
}

§ Corresponding author: Dr. P. Gautam, G.P.O. Box 9323, Kathmandu, Nepal.

Running title: Geophysical survey of subsurface karsts in Pokhara, Nepal

\begin{abstract}
Electrical resistivity (sounding with Schlumberger array and dipole-dipole imaging) and natural gamma ray intensity measurements were made over the karst features (subsurface flow-channels, solution cavities, sinkholes) in the Pokhara valley, central Nepal. In the Powerhouse area, the upper 60-80 m section of the basin-filling Quaternary sediments is represented by layered clastic sediments (gravel, silt, clay) that are represented by KQ-type $\left(\rho_{1}\left\langle\rho_{2}>\rho_{3}>\rho_{4}\right)\right.$ electrical sounding curves. The true electrical resistivity of the layers has a wide range of variation (a few hundreds to several tens of thousands of ohm.m) such that it is possible to determine both the vertical and lateral subsurface geological variations by integrating the electrical resistivity profiling and sounding techniques. Total gamma ray intensity profiles measured over various karstified locations reveal significant anomalies (up to 100 counts per second, cps) over the known or unknown subsurface openings. In the Powerhouse area, presence of a network of at least three linear NNE-SSW oriented subsurface channels, made by past and present underground flowchannels, is inferred. In interpreted electrical image profiles, contours of elevated resistivity reflect the cross-sectional geometry of cavities. The gamma-ray method is sensitive to nearsurface cavities while the electrical image effectively locates the void spaces at intermediate (up to 5-20 m) depths. An exploration program involving rapid radiometric mapping followed by selective electrical imaging is recommended for future exploration of karst-prone areas in the valley.
\end{abstract}

Keywords: Nepal, Pokhara valley, karst, electrical resistivity, radioactivity methods, Quaternary

\section{Introduction}

The Pokhara valley (c. $50 \mathrm{~km} 5 \mathrm{~km}$ ) represents an intermontane fluvial basin spread around the midstream of the Seti river in the Lesser Himalaya of Nepal. It is filled by large volume of layered clastic deposits (gravel, silt and clay), of Quaternary age, brought from the Annapurna mountain range probably by a series of catastrophic debris flows (Yamanaka et al., 1982). Due to the presence of easily soluble calcareous material (25-65\%, by volume) in the clastic sediments, 
splendid river terraces and deep gorges are carved by the Seti river and its tributaries. Karst structures (subsurface flow-channels, solution cavities, sinkholes, pinnacles, solution chimneys etc.) are widely developed both at the surface and underground. The karst structures, whether exposed or not, pose serious threat to houses, farmlands and public work of any scale (e.g., the collapse of a highway bridge over the Seti river; Dhital and Giri, 1993).

This study deals with the first results of geophysical investigations of buried karst structures in the Pokhara city, which is a site of construction works of various scales. Though we concentrated in three areas of known karst structures: the Powerhouse area in the south, Gupteshwar - Patale Chhango cave system in the southwest and Mahendra-Chamero cave system at Batulechaur in the north, we present here data from only the former two areas. Methods used are: shallow electrical resistivity sounding (symmetrical Schlumberger), electrical imaging (dipole-dipole) and radiometric gamma survey. We aimed at detection of the large-scale lateral and vertical changes in overburden lithology on the basis of electrical resistivity (Keller \& Frischknecht, 1966), appraisal of the influence of the karstic features to the resistivity-depth models at relatively small scale (e.g. Ward, 1990) and also delineation of shallow karst features by measuring the gamma ray counts (Nielson et al., 1990; Sharma, 1997), respectively. Seismic refraction and magnetometry could not be used due to strong industrial electrical/electromagnetic noise of unknown origin.

\section{Geological and Speleological Characteristics}

\subsection{Brief geological outline}

The Quaternary deposits that overlie the midland metasedimentary rocks, of Precambrian age, forming the basement in the Pokhara valley are divisible into seven formations: Begnas, Siswa, Tallakot, Ghachok, Phewa, Pokhara and Rupakot Formations (Yamanaka et al., 1982). The Ghachok, Pokhara and Phewa Formations are the major lithologies prone to the development of the karstic features (Fig. 1). The Ghachok Formation is represented by extremely hard conglomerate bed made up of sub-angular to sub-rounded gravels of limestone, sandstone and shale cemented by calcareous material. The Pokhara Formation is made up of fluvial gravels with intercalations of lacustrine sediments; the gravels comprise sub-angular to sub-rounded pebbles and cobbles of limestone and calcareous shale, which exhibit poor cementation, ill-sorting, and partial stratification. The Phewa Formation comprises well stratified, porous and comparatively weak deposits of calcarenite to calcisiltite composition.

A notable lithological unit is the gravel veneer on the fillstrath terraces carved in the Pokhara Terrace. The veneer gravels are of mainly cobble to boulder size, larger than those in the Pokhara Formation, mostly sub-rounded and scattered in unsorted sandy matrix. The clasts are represented by mainly gneiss, granite, quartzite and schist. Major geomorphologic units are: i) Ghachok Terrace and Pokhara Terrace representing the accumulational fill-top landforms; ii) two groups of fillstrath terraces developed over the Ghachok and Pokhara Terraces, respectively, representing landforms formed by redeposition over eroded ancient terraces; and, iii) recent flood plain (Yamanaka et al., 1982).

\subsection{Speleological characteristics}

Gebauer (1983) described 10 cave-sites from the western part of the Pokhara valley, of which three prominent sites of development of karst features are indicated in Fig. 1. They are: the Mahendra cave system (M) comprising of Mahendra cave and Chamero cave at the right bank of 
the Kali river; the Gupteshwar cave system (G) which comprises the Patale Chango (Devi's fall) and Gupteshwar caves formed along the course of Marde river; and, the PowerStation caves (P) which occur at the terrace scarps at the northern bank of the Phusre river (Figs. 1 \& 2). According to him, the PowerStation caves are developed in the caprock, composed of coarse conglomerate, of relatively greater resistance to weathering, constituting the uppermost part of the river terrace. The Mahendra and Chamero caves are developed below the coarse conglomerate of the caprock (which makes actually the ceilings of the caves). The Patale Chhango (or Devi's Fall) cave has a total length of $2959 \mathrm{~m}$ and a maximum depth reaching to $48 \mathrm{~m}$ and represents the longest cave in the Indian Subcontinent. He further notes that the coarse conglomeratic caprock commonly forms the ceiling of the caves.

The Mahendra and Gupteshwar caves, which are regularly visited by tourists and therefore represent the sites prone to hazard related to possible failures of certain parts, are developed within the Phewa Formation (Koirala et al., 1996). In the Powerhouse area, subsurface flow channels or caves are developed within the conglomerate layers that constitute the upper part of the Pokhara Formation. These layers are actually overlain by a coarse gravelly conglomerate of the gravel veneers or caprocks. The floor of the caves comprises sediments represented by laminated fine sand, silt and clay, which appear gray or light brown. The main entrance to the Gupteshwar cave is located at the base of a $\sim 4 \mathrm{~m}$ deep open sinkhole formed within the terrace. After entering the cave, one follows a steep course descending towards the northeast and reaches a gigantic gallery which epens up towards both sides. The southern peripheries of the Powerhouse area, Gupteshwar cave, Mahendra cave and Chamero cave area have high hazard of sinkhole development, subsidence and also widespread pollution along the subsurface solution channels (Koirala et al., 1996). The remaining part of the Powerhouse area was given a rating of medium hazard of sinkhole development and subsidence.

In the Powerhouse area, Gebauer (1983) recognized the western and eastern PowerStation caves located at $\sim 15 \mathrm{~m}$ below the cliff from the top of the terrace (Fig. 2). They lie to the east of the penstock pipes: the western one at 30m distance and the eastern one about $100 \mathrm{~m}$ further east. In 1982, the main passage of the western PowerStation cave was found hidden behind a large pile of pebbles; it was about 6 to $8 \mathrm{~m}$ broad and up to $5 \mathrm{~m}$ high resembling a temporary active river bed (Gebauer, 1983). During our survey in January 1997, the main entrance of this cave was between 15.2 and $19.2 \mathrm{~m}$ below the cliff top and had a nearly circular cross-section for about $5 \mathrm{~m}$ of the passage. The passage appeared to have greater height inside, the width and height varied and followed a complex and curved course afterwards. In the eastern PowerStation cave, according to his sketches, five entrances lead into the terrace cliff from $\sim 100 \mathrm{~m}$ long overhang. The three westernmost entrances rejoin in a $50 \mathrm{~m}$ long hall developed parallel to the terrace cliff.

\section{Geophysical Investigations}

\subsection{Field observations}

Geoelectrical investigations included sounding and imaging techniques. The equipment used comprised: SAS 300-C Terrameter (ABEM, Sweden) for imaging and DDR-2 (IGIS, India) resistivitymeter for sounding studies. For electrical sounding (ES) with Schlumbergr array, the maximum current electrode separation (AB) was limited to 100-120 m because of strong and random industrial electromagnetic noise that was induced in the cables of electrodes spaced at larger distances. For electrical imaging, a double-dipole array comprising in-line current electrodes (transmitter pair) and potential electrodes (receiver pair) was used. The distance between the nearest electrodes of the transmitter and receiver pairs was varied as a multiple (na) 
of the electrode spacing a in each pair. Measurements were made at several discrete positions as the receiver pair was moved incrementally away from the fixed transmitter pair to a maximum distance given by $n=10$. The transmitter pair was then moved by one increment (a) along the profile and the procedure was repeated. These measurements aimed at obtaining a continuous $2 \mathrm{D}$ coverage of the subsurface, as a combination of lateral profiling and vertical sounding (Telford et al., 1990), along selected profiles. The ES stations are within the irregular polygon, whereas several dipole-dipole array profiles were taken in the Powerhouse and Gupteshwar cave - Patale Chhango areas (see Figs. 2 and 5).

A GRS-500 portable differential gamma-ray spectrometer (Scintrex, Canada) equipped with 124 cc $\mathrm{NaI}(\mathrm{Tl})$ detector was used to measure the response mainly in $\mathrm{T}_{\mathrm{cl}}$ energy window (total gamma-ray counts with gamma-ray energy E $\gamma>0.08 \mathrm{MeV}$; recording period $=10 \mathrm{~s}$ ). The area mapped by gamma ray method lies within the uppermost river terrace, at the northern bank of Phusre river, shown in Figs. 2 \& 5. Gamma-ray intensity was measured at two levels (on the daylight surface or the topsoil and in air at waste height) with a spacing of 5 or $2.5 \mathrm{~m}$ along two profiles. These measurements were taken after the observations taken over the Mahendra cave where elevated gamma-ray readings were found directly over the depressions, of various scales, caused by collapse/subsidence of the ground. It was found that significant variations occur at both observation levels. The readings taken at the soil surface were higher but erratic compared to the readings taken at waste height. The latter type of measurement was preferred for mass measurement because it was almost equally informative as the former but clearly faster.

A conductivity-meter (Yokogawa, Japan) was used to measure the electrical conductivity of water samples from different rivers, lake and springs or caves.

\subsection{Interpretation techniques}

Preliminary estimation of the layer parameters (resistivity and thickness) from an electrical sounding curve was attempted by matching it with 2-layer master and auxiliary curves. The layer parameters were later used as initial estimates for further processing by iterative 1-D inversion code which combines the linear filtering and ridge regression techniques to obtain best-fit models in the least square sense (Inman, 1975; Koefoed, 1979)

The first step towards the analysis of the electrical imaging data was to plot a pseudosection in which each observed apparent resistivity value is related to the center point of the spread along the profile and the particular n-value along the vertical. Pseudosections were generated by contouring data recalculated along regular grids by triangulation/linear interpolation. Inversion of the pseudosections was done using a RES2DINV software which works on the smoothnessconstrained least-square method with implementation of quasi-Newton optimization technique (Loke and Barker, 1996). The inversion program uses a 2-D model in which the subsurface consists of an arrangement of blocks forming a layered rectangular mesh in the vertical plane. The program automatically determines the distribution of the blocks and their size so that the number of blocks does not exceed the number of datum points. For the double-dipole array, the thickness of the uppermost layer is set to 0.3 times the electrode spacing. The thickness of each subsequent layers is increased by $10 \%$ or $25 \%$. The output of the inversion is in the form of resistivity-depth model consisting of an arrangement of rectangular blocks with true resistivity values loosely tied to the distribution of datum points in the pseudosection and a calculated apparent resistivity section. The depth of the bottom row of blocks in the model is set to be approximately equal to the depth of investigation (DOI) applicable for the maximum size of the 
array obtained after Edwards (1977).

Additionally, interpretation was attempted also with another 2D-inversion software, that utilizes the concept of the sensitivity coefficients (for the underlying theory, see Dietrich, 1999). According to Dietrich (P. Dietrich, University of Tübingen, pers. comm., 2000), the DOI is regarded as a function of a specified deviation in electrical conductivity, an assumed area of deviation and a measured impedance contrast. The 2-D model used in the inversion consists of an arrangement of blocks forming a layered rectangular mesh as in the RES2DINV software with a difference that the blocks in this case are of equal size. The program assigns an initial resistivity value to each node forming the mesh and assumes smooth variation of resistivity between the nodes. This inversion scheme generates a model section that has much larger area than that represented in the corresponding pseudosection.

For all 1-D and 2-D inversion data presented in this paper, the quality of the fit between the pair of $\mathrm{m}$ data-points $(\mathrm{i}=1,2,3 \ldots \ldots . ., \mathrm{m})$ of observed apparent resistivity $\left(\rho_{\mathrm{obs}}\right)$ and calculated apparent resistivity $\left(\rho_{\text {cal }}\right)$ for the accepted model is given by a parameter called percent RMS error $\left(\varepsilon_{\mathrm{RMS}}\right)$. It is calculated as follows:

$\varepsilon_{R M S}=\sqrt{\frac{\sum_{i=1}^{m}\left\{\left(\log _{e}\left(\rho_{o b s i}\right)-\log _{e}\left(\rho_{\text {cali }}\right)\right)^{2}\right\}}{m}} \times 100 \%$

Analysis of radiometric data was carried out initially along individual profiles. A contour map was generated by gridding the dataset from adjacent profiles to correlate the visual anomalous features.

\subsection{Results of investigations}

\subsubsection{Lithological variations by ES data}

Figure 3 illustrates the typical ES curve recorded in the study area and the interpretation made to obtain estimates of the layer parameters. The equivalent models presented are those for which forward solution using the corresponding layer parameters yield curves which fit the observed values within an arbitrarily assigned $\varepsilon_{\mathrm{RMS}}$ of $10 \%$. A summary of the layer parameters is presented in Table 1. Consideration of the layer parameters obtained for the best-fitting models to ES curves for 34 stations suggests the presence of significant lithological variability in the uppermost part of the basin-filling deposits. In general, the subsurface medium comprises a fourlayer structure as follows: a) a topmost soil layer with varying moisture content ( $\rho_{1}=415$ to 1749 ohm.m; $\mathrm{h}_{1}=0.16$ to $3.87 \mathrm{~m}$ ); b) a second high-resistivity conglomerate layer known as "gravel veneer" with rounded to well rounded cobbles, boulders and pebbles in a sandy matrix $\left(\rho_{2}=2131\right.$ to $25698 \mathrm{ohm} . \mathrm{m} ; \mathrm{h}_{2}=0.7$ to $11.43 \mathrm{~m}$ ); c) the third layer of gravel, of intermediate resistivity and extremely varying thickness ( $\rho_{3}=495$ to $8728 \mathrm{ohm} . \mathrm{m} ; \mathrm{h}_{3}=0.64$ to $37 \mathrm{~m}$ ), probably with greater amount of finer material (sand and clay), low degree of cementation and relatively high moisture content; and, d) the fourth layer comprising silt and clay of lowest resistivity ( $\rho_{4}=13$ to 1793 ohm.m). The latter two layers belong to the Pokhara Formation.

Despite the possible uncertainties in ranges of the suggested layer parameters due to the principle of equivalence, the actual observations prove the general validity of the interpreted layer 
parameters. Such a four-layer sequence is exposed in a cliff near the eastern PowerStation cave where one observes: a) topsoil layer, several $\mathrm{cm}$ thick; b) compact and coarse gravel down to 5 $\mathrm{m}$; c) gravel with occasional lenses of silt down to $17.2 \mathrm{~m}$, and; d) silt with clay intercalations further below. Also, it may be noted that the second and third layer may not be very well differentiated in some curves.

Figure 4 shows the geoelectrical section based on data from ES stations located along a NW-SE profile. The ranges of true resistivity assigned to the layers are those obtained from models which best fit the observed curves used to construct this particular profile. It clearly illustrates the subsurface lithological variations. A noteworthy observation is the gradual change in the depth of the base of the gravel veneer and the third layer from both sides toward the center. The depth is maximum below Sp8 which probably represents the center of the debris fan (in Fig. 4).

\subsubsection{Delineation of subsurface flow-channels by gamma-ray counts}

A contour map of total gamma ray counts derived from eight profiles is shown in Fig. 5. The interpretation of gamma-ray counts in terms of the subsurface lithology or mass distribution is not straightforward for many reasons. The total radiation measured also involves cosmic radiation; only a fraction representing the relative differences is due to variation in local radioactivity emissions. The measured gamma-ray activity in the field is a sum of the background of the measuring instrument, intensity of cosmic rays, radioactivity of the constituent near surface rock or soil medium, effect of possible radioactive fallout, and the radon (primarily $\mathrm{Rn}^{222}$ ) content in the air. The latter is known to fluctuate with the variations in temperature, humidity and pressure, which affect the escape of radon from the rock or soil medium. With favorable circulation of radon and mineralized groundwater, the fracture and fault zones are enriched with the decay products of $\mathrm{Ra}$ and $\mathrm{Rn}$ and may be the sites of redistribution of $\mathrm{K}^{40}, \mathrm{U}^{238}$ and $\mathrm{Th}^{236}$. Despite these uncertainties, the areas lying above the karst structures are known to possess increased gamma activity due to the increased propagation of the emission along the fissures or fractures to the surface (Surbeck \& Medici, 1990; Abdoh \& Pilkington, 1989; and, a summary by Sharma, 1997). In addition, it was observed during the initial phases of this study that elevated gamma-ray readings occur over partially filled depressions, of various scales, caused by collapse/subsidence of the ground along several radiometric profiles passing over the Mahendra and Chamero caves.

From the reasons stated above, the elevated readings are attributed to the presence of subsurface channels in the study area (Fig. 5). At least three subparallel channels are inferred. The SW end of the first two channels (I and II) is marked by the PowerStation caves; a stream with significant amount of water flows out of the tunnel at the western PowerStation cave. The southern end of channel III is also a cavity seen in the terrace scarp. It is inferred that there exists an intensive network of such subsurface channels which have served as pathways for drainage of water entering from the Phewa lake (to the NW) and/or the Seti river (NE). The positive linear, subparallel to each other, anomalies resemble the radon anomalies observed over fracture zones associated with a known fault by Abdoh and Pilkington (1989). The exact mechanism giving rise to the anomalies in the study area requires further investigations (e.g., detailed differential gamma-ray spectrometer survey, determination of radon concentrations in soil samples, mapping of the distribution of clay which could be source of $\mathrm{K}^{40}$ ).

\subsubsection{Electrical imaging and resistivity-depth models}

a) Powerhouse area 
Fig. 6(a) shows the pseudosection based on data along profile IP1 with a $=5 \mathrm{~m}$ and $\mathrm{n}$-value of 1 to 10. For such a spread, the maximum depth of investigation (DOI) is $\sim 13.6 \mathrm{~m}$ following Edwards (1977) but only 10.8 m following Roy and Apparao (1971). A comparison between the results of inversion shown in Figs. 6(b) and 6(c) with those in Figs. 6(d) and 6(e) reveals that the model sections have common features in terms of resistivity distribution though there is considerable difference in the depth distribution. Assuming that the elevated resistivity regions (say $\rho>5000$ ohm.m) reflect the subsurface karst features and the depths of distribution of such features are closer to those observed at the exposed cliffs as discussed in $\$ 2.2$ above, the model in Fig 6(e) bears considerable likeness to the real situation. The differences in depth distribution may stem from the way the concept of DOI is considered during inversion, non-uniqueness of the inverse problem and the deviations of the real situation from the adapted 2D-inversion model and so on (e.g. Barker, 1989; Ward, 1990; Oldenburg \& Li, 1999).

\section{b) Gupteshwar cave}

Pseudosections constructed from the observed and calculated apparent resistivities as well as the model section obtained by RES2DINV for profile over this cave are presented in Fig. 7. As this profile has a spacing of $2.5 \mathrm{~m}$, which is half of that for IP1, the corresponding maximum DOI estimates also will be half (i.e., $6.8 \mathrm{~m}$ after Edwards, 1977 but only $\sim 5.4 \mathrm{~m}$ after Roy and Apparao, 1971). The model shows the presence of essentially two sub-horizontal layers: a high resistivity gravelly layer which serves as the medium of the development of localized near surface cavities and the underlying low resistivity layer consistent with the silty/clayey lithology of the Phewa Formation. The entrance to Gupteshwar cave described in $\$ 2.2$ lies at $\sim 10 \mathrm{~m}$ to the northwest from the center of profile ID2. Lack of high resistivity regions in the lower part of the model section suggests that the main gallery of the cave lies at depths greater than those covered by the maximum DOI of the used array.

\subsection{Electrical conductivity of water samples}

Figure 8 shows the plot of electrical conductivity of water samples from various sources (from north to south they are: Kali river, Phewa lake and canal originating from it, Seti river, cave and springs near Powerhouse, and Phusre river) and come from several localities, whose elevations are identified. The conductivity of the water samples collected from the spring or cave water is in between the conductivity range of those from Phewa lake and the Seti river. Hence, it is most likely that the water draining through the subsurface channels in the study area actually has a mixed origin from both sides, i.e. the Phewa lake and the Seti river. These data support the inferences that the terrace fan area to the north of the Powerhouse actually comprises a network of subparallel subsurface channels which are fed from the Seti river as well as the Phewa lake and canals.

\section{Conclusions}

The layered lithological structure of the Quaternary sediments filling the Pokhara basin can be mapped efficiently by the electrical resistivity sounding technique. Gamma-ray intensity profiles taken over known cave areas show the presence of positive anomalies when there are karstic features in the subsurface. Areal gamma-ray mapping of the Powerhouse area reveals linear anomalous zones which are related to subsurface channels. Model sections obtained from inversion of the electrical imaging profiles in the Powerhouse and Gupteshwar cave areas reveal 
localized high resistivity features attributable to the karstic features and layered subsurface structure, respectively. In the absence of independent data on the subsurface geology based on drilling or detailed subsurface observations even in known karst areas, it is difficult at this stage to make accurate estimates of the depth of distribution of the karstic features due to the possible nonuniqueness of the inverse geophysical problem. However, a geophysical complex involving radiometric mapping and electrical imaging seems effective in assessing the degree of development of karst features in the subsurface medium in qualitative terms.

\section{Acknowledgements}

Dr. P. C. Adhikary, Head of the Central Department of Geology, Tribhuvan University (CDG TU) and graduate students D. Bhattarai, H. Gurung and R. N. Wagle supported us in organization of the field work and data acquisition. The Kathmandu Office of Japan International Cooperation Agency and CDG TU funded the field work through a collaborative program. The manuscript benefitted from the discussions with P. Dietrich, information on shareware provided by M.H.

Loke and the critical comments of R. Guérin, N.B. Christensen and another anonymous reviewer.

\section{A JSPS invited fellowship to PG for research stay at Hokkaido University provided the} opportunity to compile this paper. We express our gratitude and appreciation to all persons and institutions involved.

\section{References}

Abdoh, A. and Pilkington, M., 1989. Radon emanation studies of the Ile Bizard Fault, Montreal. Geoexploration, 25, 341-354.

Barker, R.D., 1989. Depth of investigation of collinear symmetrical four-electrode arrays. Geophysics, 54(8), 1031-1037.

Dhital, M.R. and Giri, S., 1993. Engineering-geological investigations at collapsed the Seti Bridge site, Pokhara. Bull. Dept. Geol., Tribhuvan Univ., 3 (1), 119-141.

Dietrich, P., 1999. Konzeption und auswertung gleichstromgeoelektrischer traceversuche unter verwendung von sensitivitätskoeffiziententen (in German with English abstr.; English title: Conception and interpretation of DC-geoelectrical tracer experiments using sensitivity coefficients). Doctoral thesis, Univ. of Tübingen, Tübinger Geowissen-schaftliche Arbeiten (TGA) C50, $130 \mathrm{p}$.

Edwards, L.S., 1977. A modified pseudosection for resistivity and IP. Geophysics, 42(5), 10201036.

Gebauer, D.H., 1983. Caves of India \& Nepal. Spelälogische Sud-Asien Expedition 1981/82, Germany, 166 p.

Inman, T.R., 1975. Resistivity inversion with ridge regression. Geophysics, 40, 798-817.

Keller, G.V. and Frischknecht, F.C., 1966. Electrical Methods in Geophysical Prospecting. Pergamon Press Inc., 519 p.

Koefoed, O., 1979. Geosounding Principles, 1. Resistivity Sounding Measurements. Elsevier, Amsterdam, $276 \mathrm{p}$.

Koirala, A., Rimal, L.N., Sikrikar, S.M. and Pradhananga, U.B., 1996. Engineering and environmental geological map of Pokhara valley. Published by Department of Mines and Geology (in cooperation with BGR, Germany), Lainchaur, Kathmandu, Nepal.

Loke, M.H and Barker, R.D., 1996. Rapid least-squares inversion of apparent resistivity pseudosections by a quasi-Newton method. Geophysical Prospecting, 44, 131-152. 
Nielson, D.L., Linpei, C. and Ward, S.H., 1990. Gamma-ray spectrometry and radon emanometry in environmental geophysics. In: Geotechnical and Environmental Geophysics, Vol. 1, Soc.

Explor. Geophys., Tulsa, S.H. Ward (ed.), 219-251.

Oldenburg, D.W. and Li, Y., 1999. Estimating depth of investigation in dc resistivity and IP surveys. Geophysics, 64(2), 403-416.

Roy, A. and Apparao, A., 1971. Depth of investigation in direct current methods. Geophysics, 36(5), 943-959.

Surbeck, H. and Medici, F. , 1990. Rn-222 transport from soil to karst caves by percolating water. In: Proc. 22nd Congr. IAH, Aug. 27-Sept. 1, Lausanne.

Sharma, P.V., 1997. Environmental and Engineering Geophysics. Cambridge Univ. Press., 475 p.

Telford, W.M., Geldart, L.P. and Sheriff, R.E., 1990. Applied Geophysics. Cambridge University Press, $770 \mathrm{p}$.

Ward, S.H., 1990. Resistivity and induced polarization methods. In: Geotechnical and

Environmental Geophysics, Vol. 1, Soc. Explor. Geophys., Tulsa, S.H. Ward (ed.), 147-189.

Yamanaka, H., Yoshida, M. and Arita, K., 1982. Terrace landform and Quaternary deposits around Pokhara valley, Central Nepal. J. Nepal Geol. Soc., 2, 95-112.

\section{Figure and Tables}

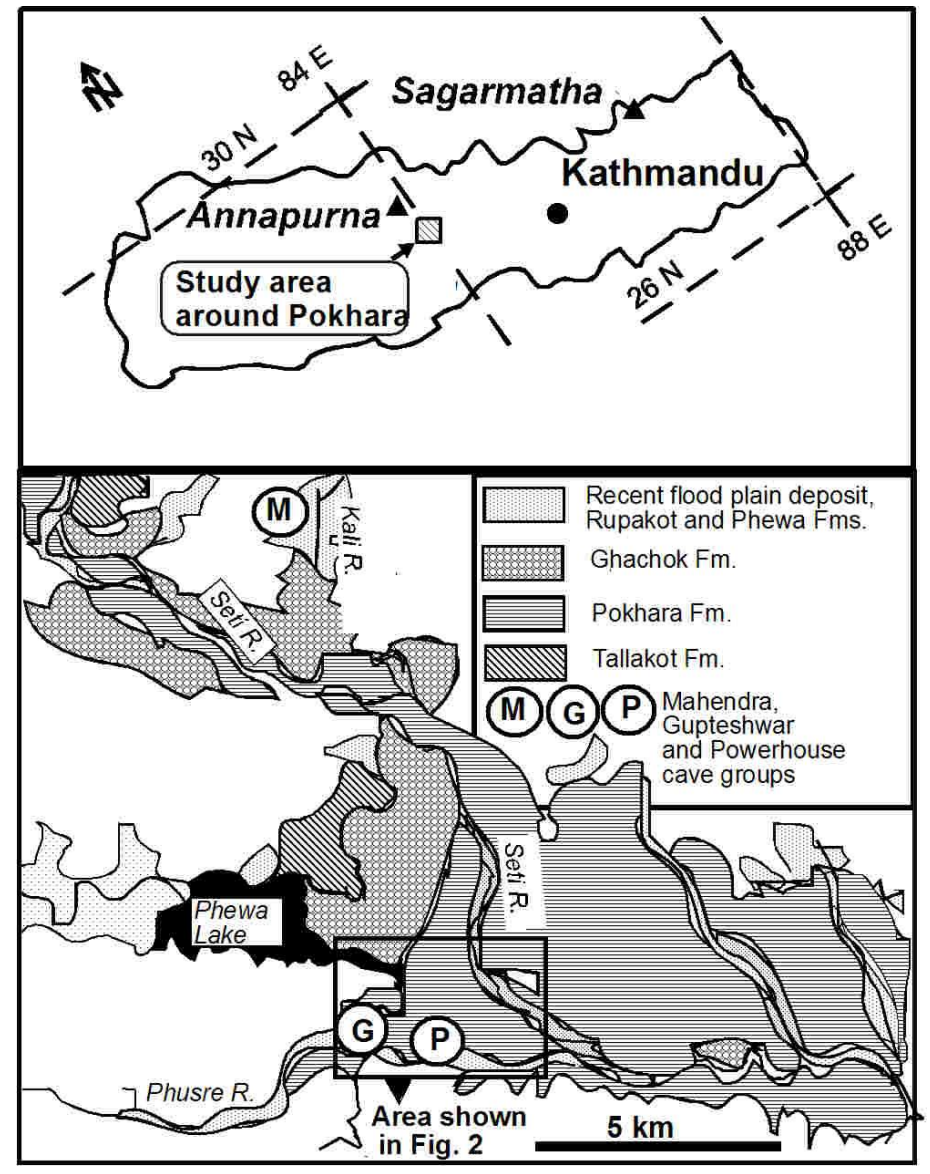

Fig. 1. Sketch map of Nepal showing the study area in Pokhara valley (upper diagram) and schematic geologic map with major lithological units (lower diagram; adapted from Yamanaka et al., 1982). The Pokhara city lies at $\sim 28^{\circ} 12^{\prime}$ $\mathrm{N}$ latitude and $83^{\circ} 58^{\prime} \mathrm{E}$ longitude. The Phewa lake is shown in dark color. Three prominent localities of the karstic features or caves (M, G and P) are shown after Gebauer (1983). 


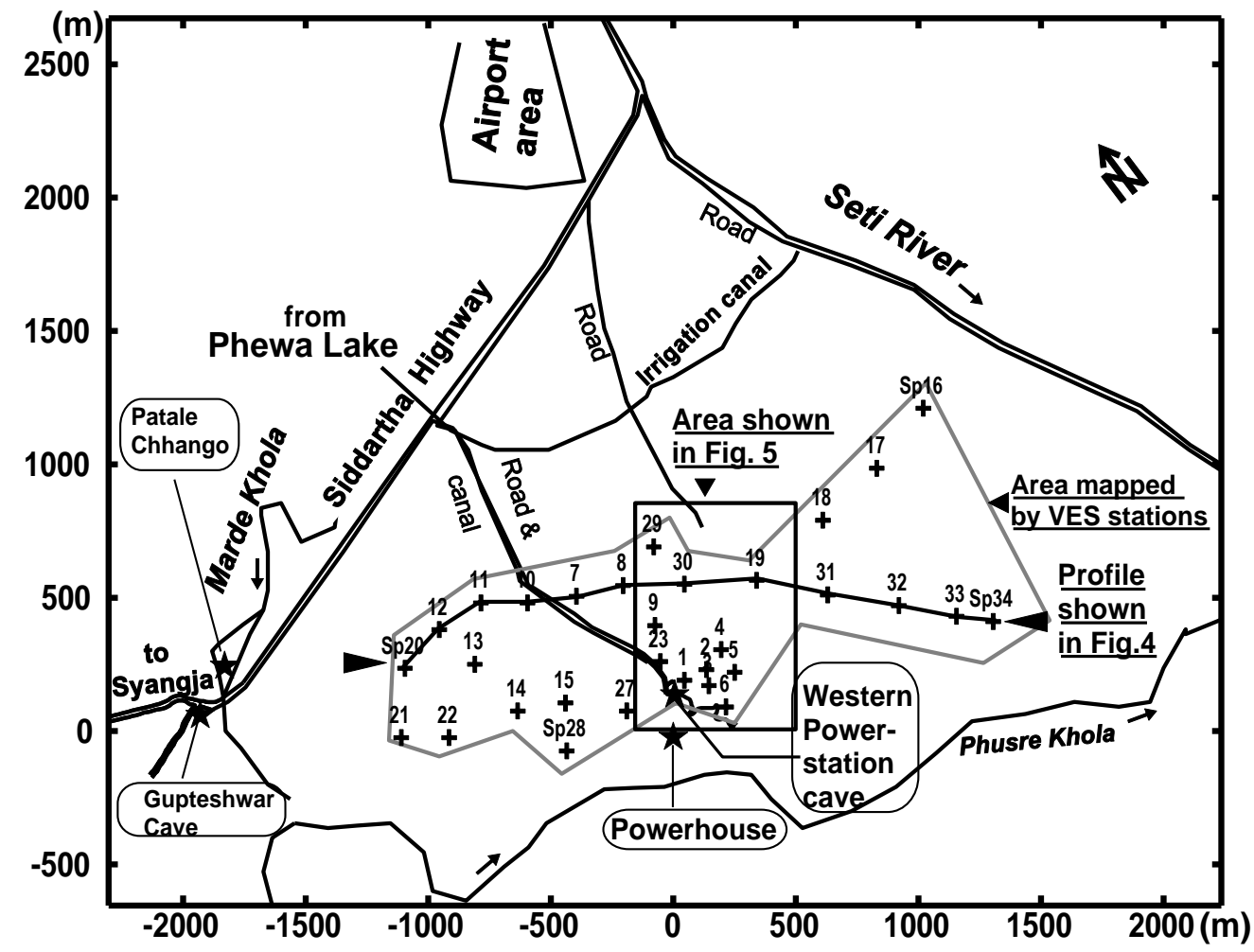

Fig. 2. The Powerhouse- Chhorepatan area. Locations of major caves (stars: Patale Chhango or Devi's Fall, Gupteshwar cave, western PowerStation cave). The irregular polygon shows the area studied by electrical sounding (ES). The stations are identified by numbers (for clarity, only a few of them are preceded by "Sp" meaning sounding point).

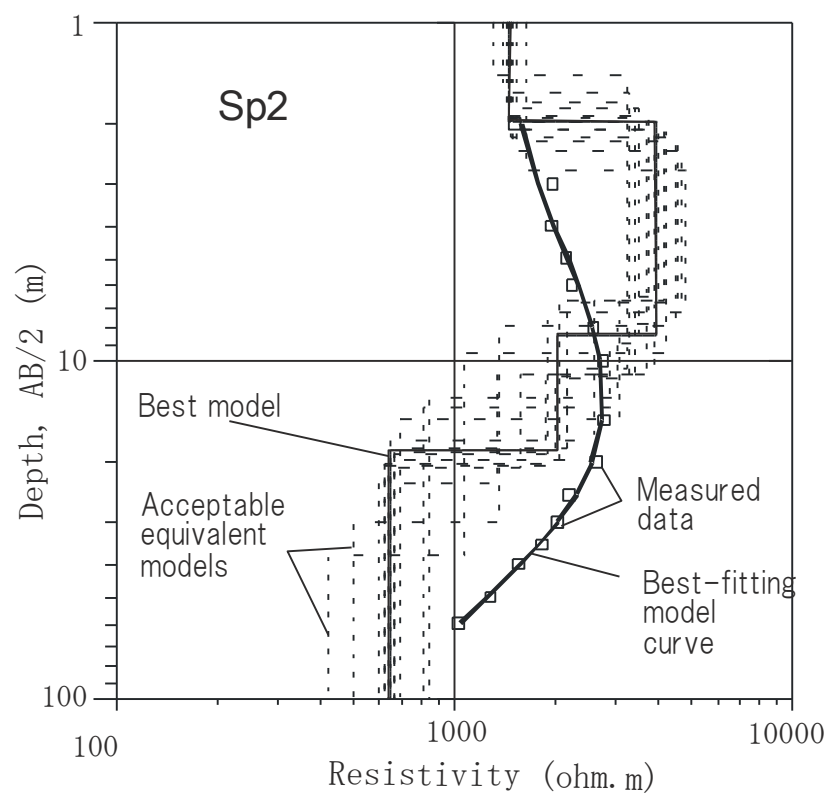

Fig. 3. Bilogarithmic plots showing a typical electrical sounding (Schlumberger array) curve and its interpretation in terms of layered models. Both the apparent resistivity (for measured and fitted curves) and true resistivity (for the models) share the same horizontal axis; the electrode spacing $(\mathrm{AB} / 2)$ and depths to the different layers share the same vertical axis. The RMS error $\left(\varepsilon_{\mathrm{RMS}}\right)$ for the best-fitting curve is $3.8 \%$ while it has a maximum value of $10 \%$ for the equivalent models shown. The layer parameters are listed in Table 1. 


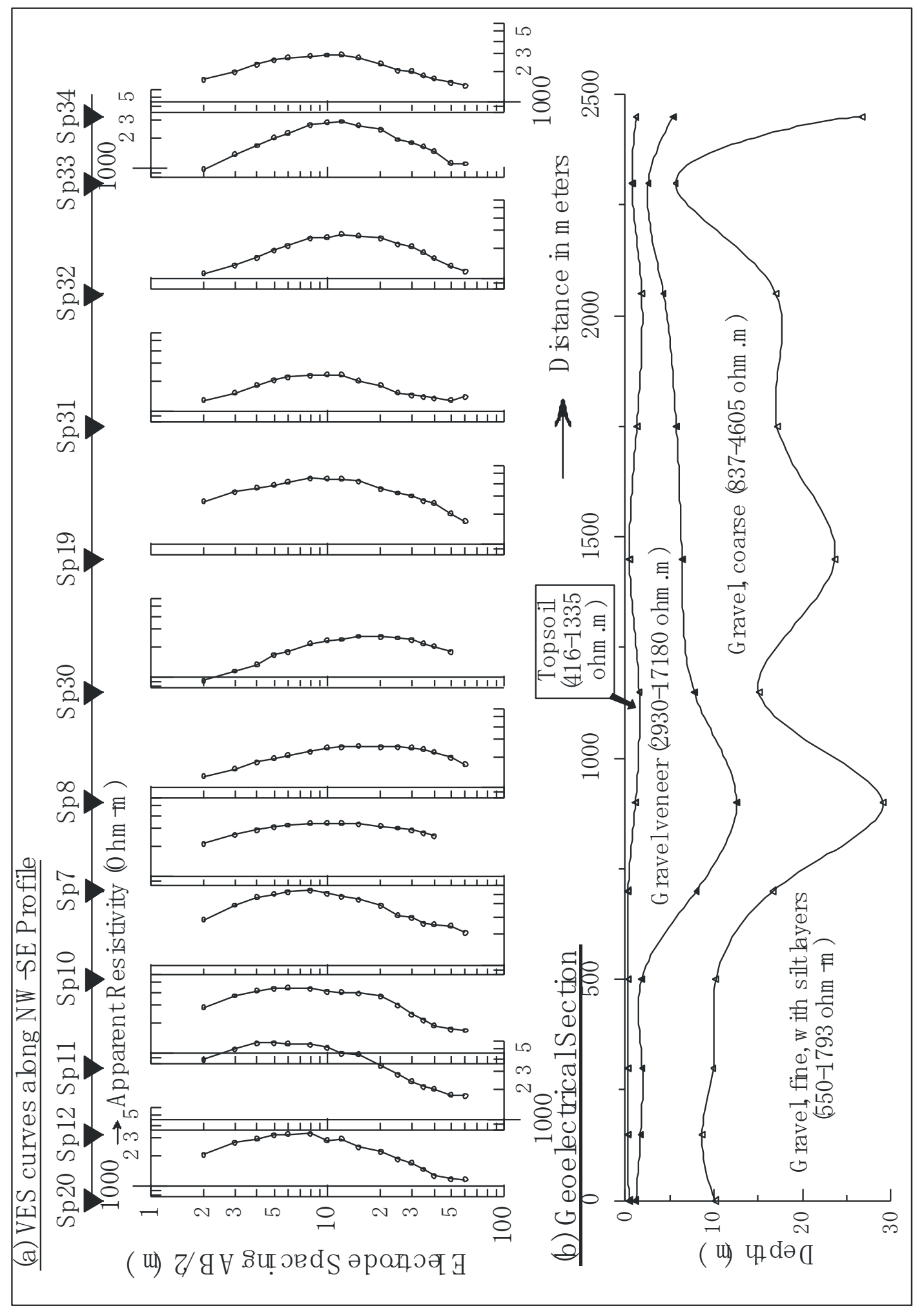

Fig. 4. The electrical sounding (with Schlumberger array) curves and the interpreted geoelectrical section along a NW-SE profile (see Fig. 2. for location). 


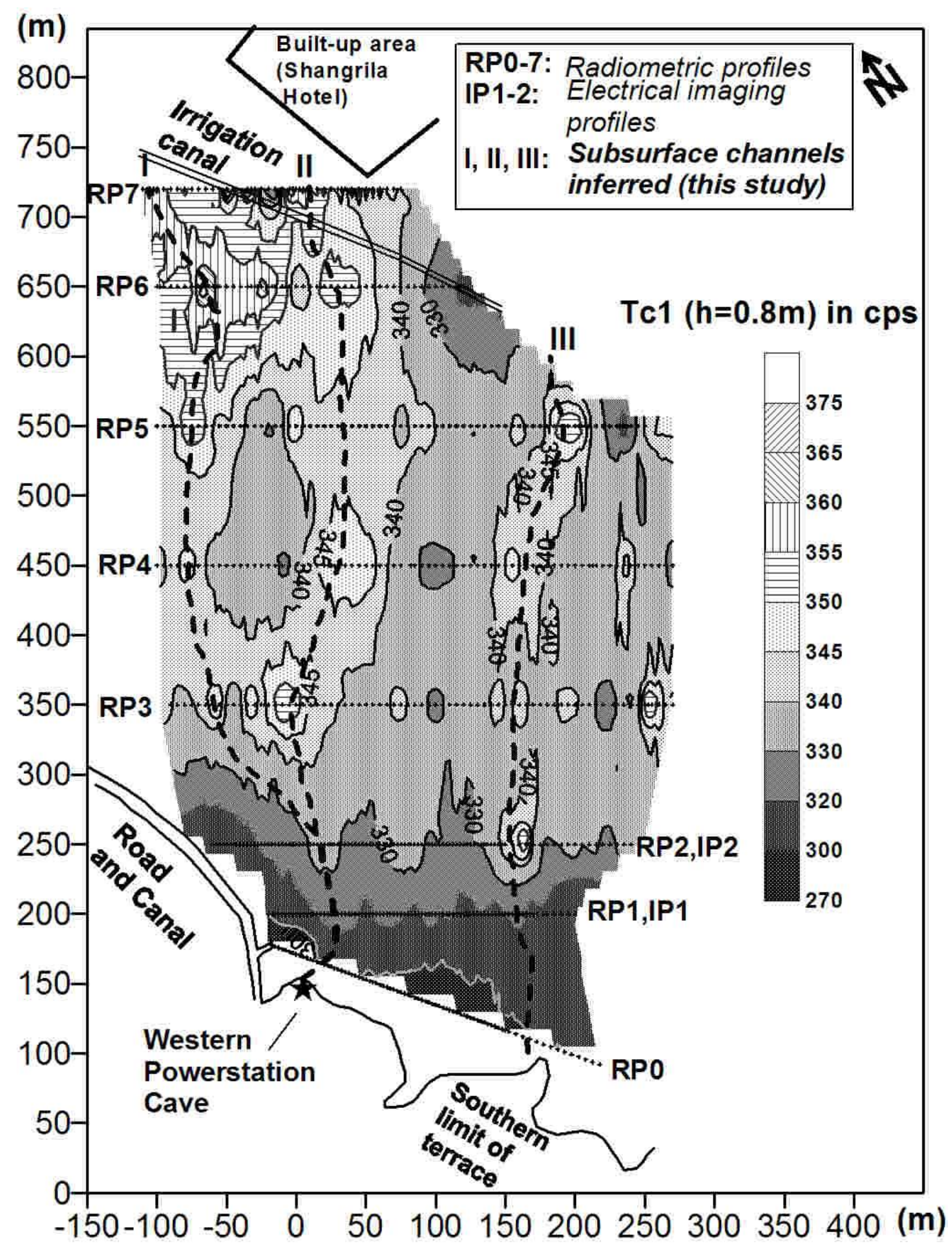

Fig. 5. Contour map of total gamma ray counts recorded by a gamma-ray spectrometer in area lying between Powerhouse and Shangrila Hotel area. For location see Fig. 2. RP0-RP7: radiometric profiles; IP1-IP2: imaging (resistivity) profiles. Discontinuous lines show the inferred traces of three subsurface channels marked by anomalous counts in the map. 
(a) Observed apparent resistivity pseudosection

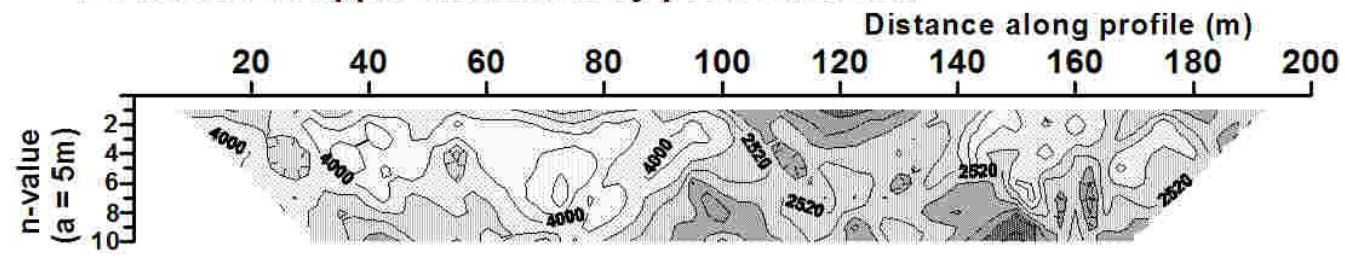

(b) Calculated apparent resistivity for model resistivity section 1

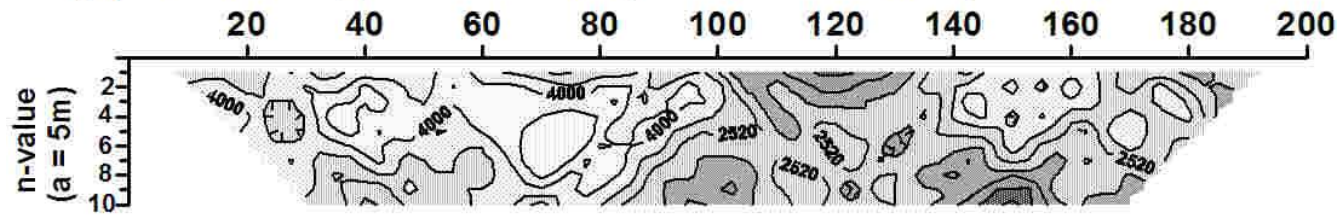

(c) Model resistivity section 1

RMS Error $=8.8 \%$

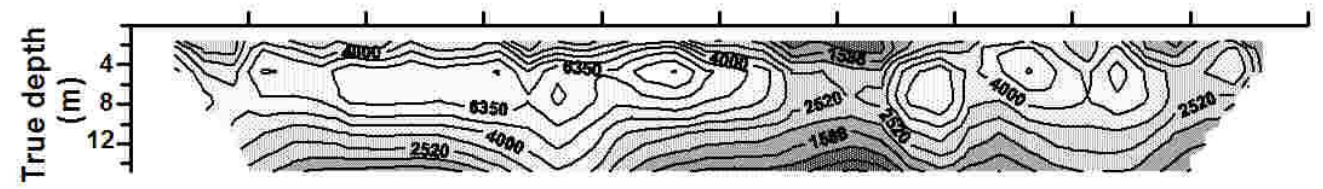

(d) Calculated apparent resistivity for model resistivity section 2

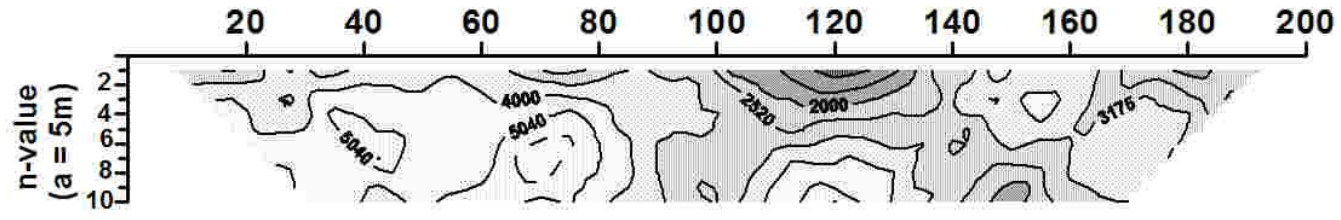

(e) Model resistivity section 2

RMS Error $=26.7 \%$

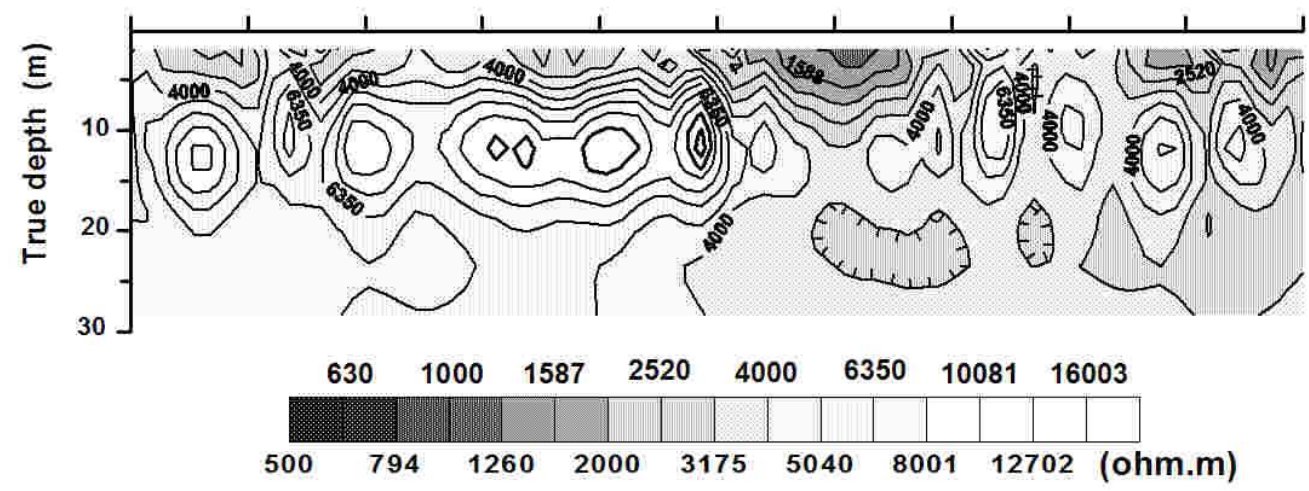

Fig. 6. Results of electrical imaging by dipole-dipole array along profile IP1 from the Powerhouse area (see Figs. 2. and 5 for profile location). (a): Measured data ; (b)- (c): Results of 2D-inversion following the scheme of Loke and Barker (1996); and (d)-(e): Results of 2D-inversion after Dietrich (1999). Though the models show similar shapes, the depth distribution of objects of contrasting resistivity differs significantly. Model section (c) is the best mathematical solution as it has low $\varepsilon_{\text {RMS }}$. The model section (e) is a second choice on the basis of $\varepsilon_{\text {RMS }}$ but seems to be a closer match to the observed and expected depth of distribution of the buried void spaces characterized by elevated resistivities. 


\section{(a) Observed apparent resistivity pseudosection}

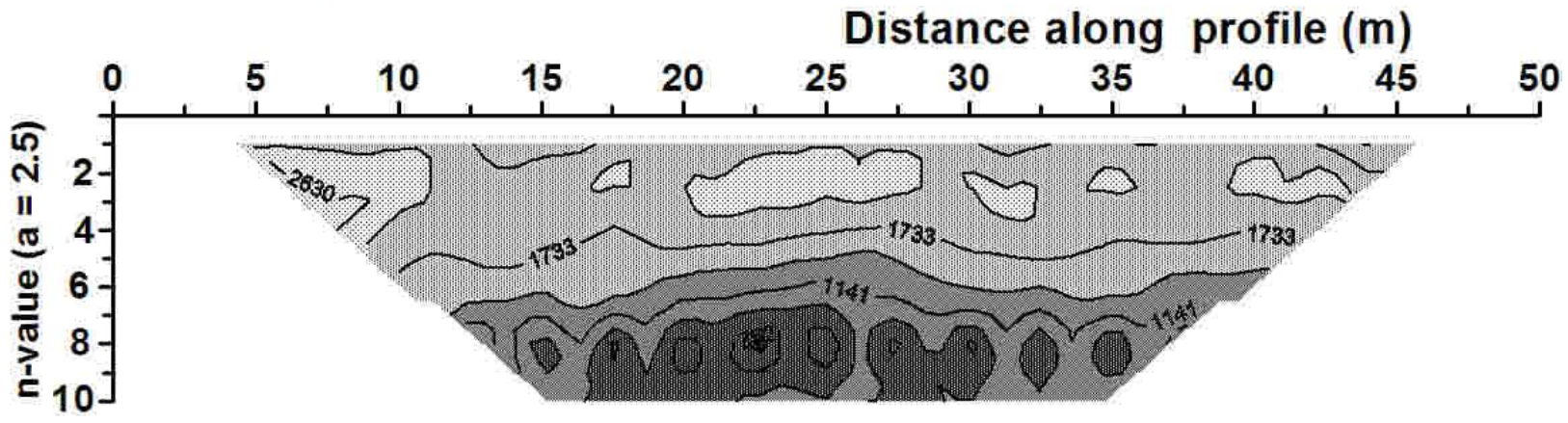

\section{(b) Calculated apparent resistivity pseudosection}

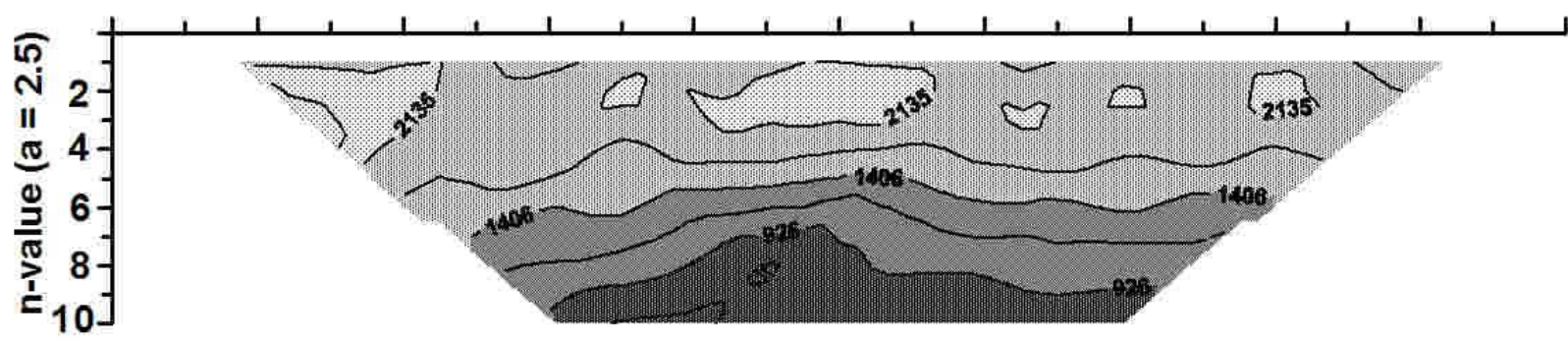

(b) Model resistivity section

RMS error $=11.9 \%$

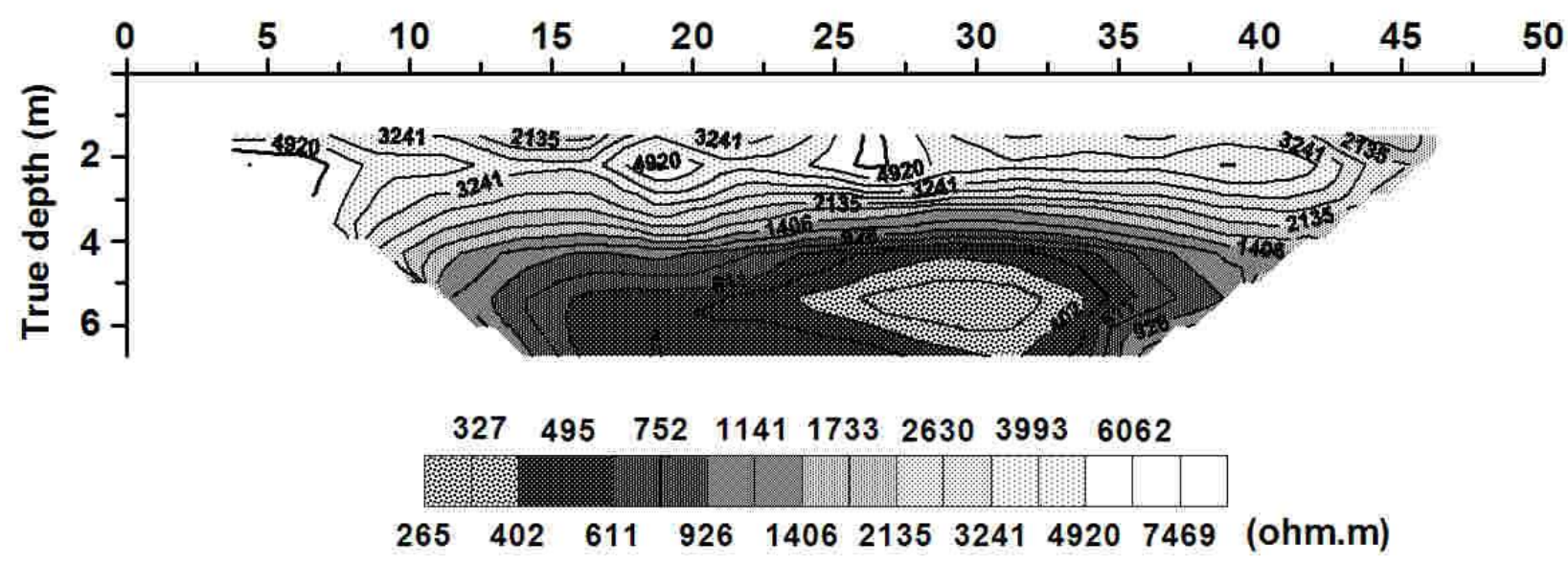

Fig. 7. Results of electrical imaging by dipole-dipole array along profile ID2 over the Gupteshwar cave. (a): Measured data; and, (b)- (c): Results of 2D-inversion following the scheme of Loke and Barker (1996). The model section suggests the presence of at least 6-7 $\mathrm{m}$ thick two-layer subsurface structure over the Gupteshwar cave. 


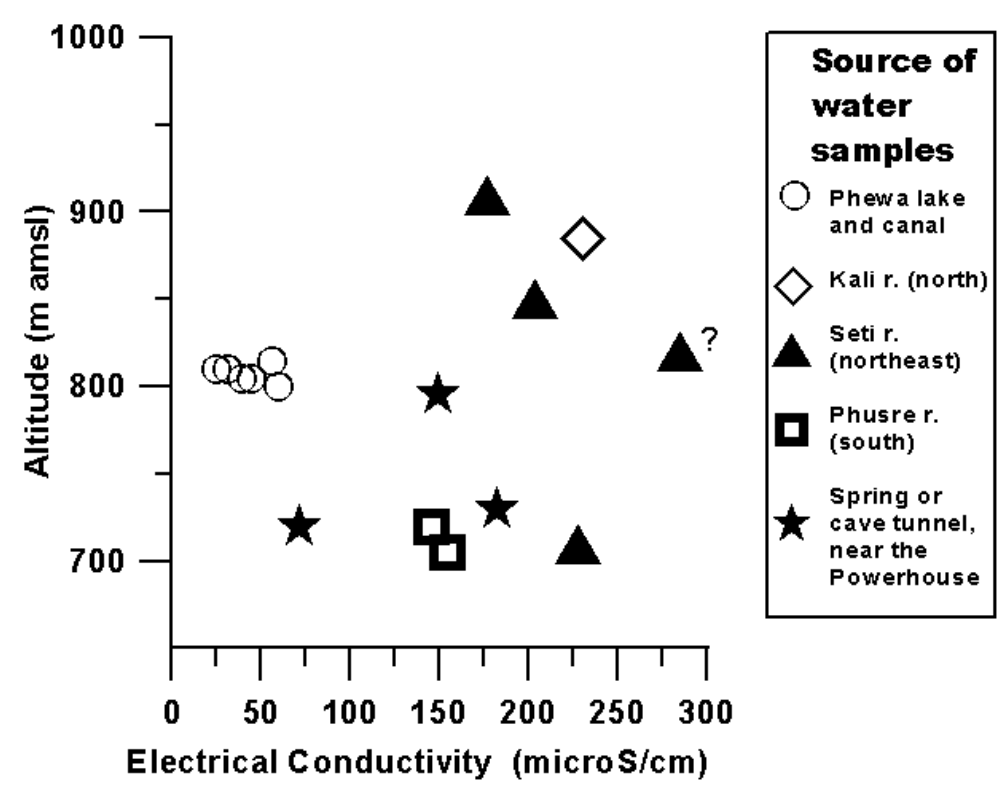

Fig. 8. A plot of the electrical conductivity (EC) vs. altitude for water samples from various sources within the Pokhara basin. The temperature (source) of the water samples were as follows: $15.5-20.0^{\circ} \mathrm{C}$ (Phewa lake and canal); $17.7{ }^{\circ} \mathrm{C}$ (Kali river); $12.2-18.3^{\circ} \mathrm{C}$ (Seti river); $18.7-19.3{ }^{\circ} \mathrm{C}$ (Phusre river); and 16.6-23. ${ }^{\circ} \mathrm{C}$ (spring or cave water). The spring water sample plotting at the left side (from east of the PowerStation), with lowest conductivity, is believed to originate from the Phewa lake. The other two spring/cave water samples plotting in the right side seem to have large influence of the Seti river water. A high EC value recorded from the Seti river at $820 \mathrm{~m}$ altitude is difficult to explain and is marked with a question mark.

Table 1

Summary of layer parameters based on interpretation of a typical sounding curve (Sp2)

\begin{tabular}{|c|c|c|c|c|c|c|c|c|}
\hline \multicolumn{5}{|c|}{$\begin{array}{l}\text { Parameters for the best-fitting model } \\
\text { (with } 3.8 \% \text { RMS error) }\end{array}$} & \multicolumn{4}{|c|}{$\begin{array}{l}\text { Limits for equivalent models } \\
\text { (with up to } 10 \% \text { RMS error) }\end{array}$} \\
\hline \multirow[t]{2}{*}{ Layer No. } & \multirow[t]{2}{*}{$\begin{array}{l}\text { Resistivity } \\
\text { (ohm.m) }\end{array}$} & \multirow[t]{2}{*}{$\begin{array}{l}\text { Thickness } \\
\text { (m) }\end{array}$} & \multirow{2}{*}{$\begin{array}{l}\text { Longitudinal } \\
\text { conductance } \\
\text { ( } \mu \text { Siemens) }\end{array}$} & \multirow{2}{*}{$\begin{array}{l}\text { Transverse } \\
\text { resistance } \\
\left(\text { ohm. } \mathrm{m}^{2}\right)\end{array}$} & \multicolumn{2}{|l|}{$\begin{array}{l}\text { Resistivity } \\
\text { (ohm.m) }\end{array}$} & \multicolumn{2}{|c|}{$\begin{array}{l}\text { Thickness } \\
(\mathrm{m})\end{array}$} \\
\hline & & & & & Min. & Max. & Min. & Max. \\
\hline 1 & 1451 & 1.96 & 1360 & 2855 & 1303 & 1622 & 1.44 & 2.72 \\
\hline 2 & 3930 & 6.41 & 1630 & 25201 & 3221 & 4835 & 4.33 & 9.55 \\
\hline 3 & 2008 & 10.07 & 5010 & 20222 & 1071 & 3079 & 4.89 & 28.27 \\
\hline 4 & 641 & & & & 421 & 845 & & \\
\hline
\end{tabular}

(End of the manuscript) 